\title{
Desafios para professores no século 21
}

\section{Challenges for teachers in the 21st century}

\author{
Alicia Sánchez Jaimes \\ Mestre em Psicologia Clínica, Faculdade de Psicologia da Universidade Nacional \\ Autônoma do México \\ Instituto Politécnico Nacional, Centro de Estudos Científicos e Tecnológicos No. \\ 13 \\ Endereço: Calz Taxqueña 1620, Paseos de Taxqueña, Coyoacán, 04250 Cidade \\ do México, CDMX \\ E-mail: asanchezja@ipn.mx
}

\section{RESUMO}

Dentro da sociedade, a escola tem desempenhado um papel muito importante, sendo uma instituição que contribui para que os alunos se tornem pessoas que num futuro não muito distante se tornem adultos responsáveis; capaz de contribuir para a construção de um mundo melhor, no qual os direitos humanos sejam respeitados e os valores éticos aplicados para a manutenção de uma sociedade harmoniosa.

Palavras-chave: Educação, Desafios, Professor, Século XXI, Tecnologia.

\section{ABSTRACT}

Within society, the school has played a very important role, being an institution that helps students become people who, in the not-too-distant future, will become responsible adults; capable of contributing to the construction of a better world, in which human rights are respected and ethical values applied to the maintenance of a harmonious society.

Keywords: Education, Challenges, Teacher, 21st Century, Technology.

\section{INTRODUCCIÓN}

A pesar de que existe una variedad en los sistemas educativos dependiendo de la latitud geográfica y de los contextos económicos, ninguno es ajeno al propósito original, tratando de cumplir con el papel de insertar a las personas dentro del mundo de los conocimientos, así como también propiciar la socialización con pares, lo que a final de cuentas conlleva a aprender a vivir en sociedad. 
Entre las múltiples contribuciones que los ambientes educativos han dado a la humanidad, está el que han favorecido convivir dentro de un ámbito social, lo cual significa regirnos por normas, respetarlas y adaptarnos a las diferentes personas y situaciones en las que coexistimos.

A través del tiempo los modelos educativos se han transformado como consecuencia de los cambios sociales, políticos, económicos, etc. Observando los cambios que se han generado a lo largo de la historia podemos percatarnos de la forma en que el alumno se ha relacionado con el conocimiento; antes no tenía la posibilidad de construir su propio conocimiento, era un sujeto pasivo que asumía un papel pasivo de receptor, memorizador y repetidor del conocimiento que otro le había ofrecido en una dinámica de comunicación totalmente vertical.

Hay cambios que se han hecho inaplazables, el siglo XXI plantea un reto que deben enfrentar los centros educativos, ya no es suficiente enseñar, sino que hay que estimular el deseo por aprender. Así como promover una metamorfosis en las relaciones interpersonales que se desarrollan al interior de éstos, en las que se reflejen valores como la equidad, el respeto y la aceptación de las otredades como una forma de enriquecimiento personal y social.

De un tiempo a nuestros días, se han sufrido cambios drásticos en la comunidad educativa; ya que además de incluir tópicos que convergen en el desarrollo de la esfera cognitiva, comunicativa, social, valorativa y práctica (De Subiria, 209), se ha incorporado la tecnología.

Se ha visualizado que la introducción de todas las herramientas y recursos de la tecnología y la comunicación tiene la potencialidad de coadyuvar en la transformación de los sistemas educativos, orientándolos hacia un mecanismo mucho más flexible y eficaz que permita mejorar la práctica docente.

En la actualidad las escuelas se enfrentan a requerimientos de la sociedad del conocimiento en donde se han transformado las viejas prácticas docentes en espacios en los que se crean nuevas formas de apropiación y renovación del conocimiento.

En 2006 Krüger señala que la sociedad del conocimiento se caracteriza por haber sustituido el trabajo, las materias primas y el capital por el 
conocimiento percibido como la plataforma hacia el crecimiento y la productividad. Por esto, la nueva sociedad generada a partir del conocimiento hace suyas las necesidades que se generan en el entorno.

Existen muchos investigadores como Lubián (2011) que adjudican los cambios vertiginosos a la Economía y a la Tecnología en su amplia acepción. Dado nuestro objeto de estudio nos enfocamos en: las tecnologías de información y comunicación que han permeado de manera muy importante en la educación.

Frente a este panorama que nos ofrece la sociedad del conocimiento se vuelve inevitable contar con personas aptas, que cuenten con las habilidades ad hoc a las demandas sociales actuales. Por tal motivo, debemos contemplar en los programas de estudio, las competencias que se deben desarrollar para generar nuevos aprendizajes que estén acordes a nuestro mundo.

\section{2 ¿QUÉ DEBEMOS HACER ANTE ESTE DESAFÍO?}

En nuestros días se vive una turbulencia que nos enfrenta a cambios rápidos y de manera constante, por lo que se hace necesario adaptarse a esta vorágine de transformaciones; sin perder de vista que ante todo debe mantenerse la idea de construir sociedades más humanas (Natividad Robles Aguilar, 2019)

En la actualidad, los ambientes laborales demandan que los egresados de carreas tanto técnicas como profesionales deben contar con habilidades técnicas y tecnológicas y conocer las tendencias globales porque ello nos permita orientar nuestro desarrollo de destrezas hacia objetivos universales.

Vivimos en una constante escalada la que se demanda hacia una sociedad inmersa en la tecnología; debemos de incorporar nuevas herramientas que redunden en nuevos proyectos que sean viables en un corto plazo.

La industria 4.0 nos envía a una realidad que antes veíamos lejana, pero que ya forma parte de nuestro presente, lo que implica que debemos desarrollar habilidades relacionadas con las tecnologías; esto es el manejo de datos, el 
incidir en la realidad virtual e inteligencia artificial. Estamos frente a una situación en la que cada vez más "todo está conectado a la tecnología".

La tecnología se desarrolla no necesariamente en los espacios académicos, en las aulas o en los laboratorios, sino hay que tener contacto con ese espacio que queremos transformar "El mundo está allá afuera"

Los futuros profesionistas no solo deben ser expertos en matemáticas y lenguaje, sino en todas aquellas áreas que les ayuden a estar calificados para las carreras del futuro, por tal razón es fundamental que los sistemas educativos pongan en un primer plano la tecnología como una herramienta primordial para el desarrollo de los jóvenes.

En este momento, un gran desafío para los profesores se focaliza en como formar a los futuros profesionistas que den respuesta a las exigencias laborales. Se ha dicho que la robótica y la inteligencia artificial han dado origen a la cuarta revolución industrial (Schwab, 2017) y para estar acorde es conveniente desarrollar $\mathbf{1 0}$ habilidades blandas que requiere la industria:

\author{
La solución de problemas \\ El pensamiento crítico \\ La creatividad \\ Gestión de recursos humanos \\ Coordinación con otros \\ Inteligencia emocional \\ Juicio y toma de decisiones \\ Orientación hacia el servicio \\ Capacidad de negociación \\ Flexibilidad cognitiva.
}

Los profesionales de la educación debemos tener claro que la transmisión de conocimientos tradicional fue rebasada y para mantenernos a la vanguardia debemos coadyuvar en el desarrollo de diferentes tipos de competencias que están presentes en las sociedades del conocimiento (Trilling y Fadel, 2009): 
1) Creatividad e innovación. - que conduzcan a una actitud de apertura, viendo los errores como una posibilidad de aprender. Esto puede lograrse utilizando los diferentes tipos de razonamiento; el deductivo y el inductivo, así como viendo al todo y a las partes.

2) Pensamiento crítico. - para favorecer la resolución de problemas, promoviendo el planteamiento y análisis de diferentes puntos de vista, que redunde en la solución de situaciones problemáticas que se presentan en los diferentes escenarios en los que se interactúa.

3) Acceder a la información de manera eficiente y eficaz utilizándola de manera precisa y creativa. Así también, emplear la tecnología como un instrumento para investigar, organizar, evaluar y comunicar información.

4) Pensamiento computacional. - que sirve para desarrollar estrategias cognitivas y metacognitivas basadas en estrategias, conocimientos y técnicas informáticas.

La UNESCO (2011), planteo que es imperioso el uso de las TIC para propiciar el desarrollo de competencias del siglo XXI y para la construcción y cocreación del conocimiento.

Actualmente, el trabajo colaborativo se efectúa a través de aplicaciones en diferentes plataformas digitales, en las cuales podemos compartir y trabajar sobre un tema en específico de manera simultánea con otras personas. De esta manera quedaron atrás variables como el espacio, lo trascendental de este planteamiento radica en que los alumnos sientan como propia la tecnología.

La interacción virtual otorga la posibilidad de un cambio en la estructuración y en la construcción del aprendizaje, así también le brinda a la persona la posibilidad de acercarse a otro nivel de conocimientos cuando él lo considere conveniente; de tal suerte que lejos de vivirlo como una obligación, lo goce y pueda sentir placer por aprender.

Es fundamental, vislumbrar que el mundo virtual no reemplaza al mundo físico, sino que lo hace crecer, ofreciéndole una multiplicidad de posibilidades, los 2 escenarios son complementarios. 


\section{具佘 EDUCATION}

\section{CONCLUSIONES}

Es irrefutable que la calidad de la docencia está vinculada a la calidad de los procesos de aprendizaje, sin embargo, no es la única variable que se debe contemplar para hacer una evaluación y los ajustes correspondientes.

Es inaplazable, tenemos un compromiso social: debemos construir una profesión docente de calidad, lo cual resulta un reto dado que nuestra actividad profesional se desarrolla en un contexto complejo, con poca estabilidad y hasta cierto punto vulnerable.

El desafío se estructura al contestar este cuestionamiento: ¿Qué docente requiere la sociedad del conocimiento y de la tecnología? Debe ser un profesional que posea los conocimientos propios de su área de competencia, que cuente con las herramientas pedagógicas y de la tecnología de la información y de la comunicación que sirvan de catalizador para construir, compartir y socializar los conocimientos.

Y por último, y no por ello menos importante el docente del siglo XXI debe fungir como un agente promotor en la construcción de una sociedad más democrática, justa y más libre. 


\section{具佘 EDUCATION}

\section{REFERENCIAS}

Coordinación de Universidades Politécnicas (2005). Modelo Educativo Basado en Competencias del subsistema de Universidades Politécnicas. México: CUP. Educ.ar (01 de junio de 2016).

Sociedad del conocimiento. Disponible en:

http://coleccion.educ.ar/coleccion/CD26/datos/sociedad_conocimiento.html.

Consultado en: 10/03/2021 a las 13:00.

Davini, M. (1997). La formación docente en cuestión: Política y Pedagogía. Buenos Aires:

Paidós.

De Zubiría, J. et al (2009). Los ciclos en la educación. Bogotá: Editorial del MagisterioFierro, K y Rosas L. (1999). Transformando la práctica docente. Una propuesta basada en la

investigación-acción. México: Paidós 